\title{
Is Process Simulation Effectively Utilized in Chemical Engineering Courses
}

\author{
Mariano J. Savelski, Kevin Dahm, and Robert P. Hesketh \\ Rowan University \\ Chemical Engineering \\ 201 Mullica Hill Rd, \\ Glassboro, NJ 08028-1701
}

Submitted to 2001 ASEE Annual Conference, Session 3513, June 27, 2001

\begin{abstract}
Process simulators are being used extensively in senior level chemical engineering design courses, and are becoming more prevalent in lower level courses. This paper explores the impact of chemical engineering programs starting to integrate process simulators throughout the curriculum. We will assess the features of process simulators that are easy to use and are effective in communicating chemical process principles. In addition, we will examine aspects of simulators that are difficult for students to comprehend, use and result in a poor utilization of educational resources. What are the possibilities for courses that traditionally do not use process simulators because standard models have not been incorporated in process simulation? Another aspect that will be discussed will be that many graduates will work for companies that do not currently use process simulators. In many cases these companies include future growth opportunities for chemical engineers including pharmaceuticals, bioprocessing and membrane applications. If a large percentage of students that are trained in process simulators do not use them, then is integrating process simulation an effective use of educational time at the undergraduate level? What issues are brought about when students become dependent on process simulation results and are not able to perform hand calculations for an industry without process simulation?

\section{Background}

Process simulators are becoming a basic tool in chemical engineering programs. In Senior level design the semester design project typically involves the use of either a commercial simulator or an academic simulator such as ASPENPLUS, ChemCAD, ChemShare, FLOWTRAN, HYSYS, and PROVISION (PRO/II). Many of the design textbooks are including simulation exercises specifically prepared for a particular simulator. For example the text by Seider, Seader and Lewin (1999) ${ }^{1}$ has examples of ASPEN Plus and HYSYS. In addition optimization problems in GAMS ${ }^{2}$ are given as well as dynamic simulation exercises in DYNAPLUS ${ }^{3}$ and HYSYS. Professor Lewin is preparing a new version of the courseware, contained in the Seider, Seader and Lewin text, on a CD-ROM giving tutorials on the use of HYSYS throughout the curriculum. ${ }^{4}$
\end{abstract}


In this paper, we analyze how effective is to include process simulation in the chemical engineering curriculum, vertical integration of process simulation vs. the traditional usage in the senior design courses, and the real pedagogical value based on industry needs and future technology trends.

\section{Discussion}

In the past, most chemical engineering programs have seen process simulation as a tool to be taught and used solely in senior design courses. In this traditional approach, seniors are usually introduced to process simulation in their fall semester through homework and computer labs and then, they are expected to fully use the simulator to perform mass and energy balances, try alternative design schemes, and optimize the most appropriate design. All these tasks are usually done during the spring semester capstone design project. Lately, the chemical engineering community has seen a strong movement towards the vertical integration of design throughout the curriculum. Some of these initiatives are driven by the new ABET criteria. This integration could be highly enhanced by an early introduction to process simulation.

Process simulation can also be utilized in lower level courses as a pedagogical aid. The thermodynamics and separations area have a lot to gain from simulation packages. One of the advantages of process simulation software is that it enables the instructor to present information in an inductive manner without the need for time-consuming experiments. For example, in a course on equilibrium staged operations, among the concepts a student must learn are the optimum feed location. Standard texts such as Wankat (1988) ${ }^{5}$ present these concepts in a deductive manner.

Some courses in chemical engineering, such as process dynamics and control and process optimization, are computer intensive and can benefit from dynamic process simulators and other software packages. Henson and Zhang $(2000)^{6}$ present an example problem where HYSYS.Plant, a commercial dynamic simulator, is utilized in the process control course. The process features the production of ethylene glycol in a CSTR and the purification of the product trough distillation. The authors utilize this simple process to illustrate concepts such as feedback control and open-loop dynamics. Clough $(2000)^{7}$ presents a good overview of the usage of dynamic simulation in teaching plantwide control strategies.

A potential pedagogical drawback to simulation packages such as HYSYS and ASPEN is that it might be possible for students to successfully use models without really understanding the physical phenomena within each unit operation. Clough (2000) emphasizes the difference between "students using vs. student creating simulations". Care must be taken to insure that simulation enhances student understanding, rather than providing a crutch to allow them to solve problems with only a surface understanding of the processes they are modeling. Howat $(1988)^{8}$ emphasizes that the capstone design course must focus on creativity -- synthesis and evaluation. This course should also focus on developing the confidence to practice. He concludes by stating that any interference that detracts from this should be rooted out and discarded. This concern has motivated the development of phenomenological modeling packages such as ModelLA ${ }^{9}$. Instead of presenting the user with a set of hardwired unit 
operations to choose from, ModelLA requires the user to construct models out of units that are control volumes with specific physical features: liquid-liquid equilibrium units, liquidvapor equilibrium units, black box units, etc. In such an environment, the user must determine how to translate the physical phenomena being modeled into the language of ModelLA, and thus cannot successfully complete a model without understanding the process in detail.

\section{Chemical Process Simulation and Computer Survey}

In 1996, CACHE conducted a survey that shows the influence of computers and programming in the chemical engineering curriculum but little emphasis was placed in the use of process simulators. To fill this gap, a survey on computer usage in the chemical engineering curriculum was distributed to U.S. chemical engineering department heads. (In many cases it was forwarded to a department design specialist for completion.) The survey addressed how extensively simulation software is used in the chemical engineering curriculum, as well as motivation for its use. The use of mathematical software and computer programming was also addressed. Preliminary results are presented here; the response rate as of this writing was $17 \%$.

In their 1996 study on computing skills in chemical engineering curriculum, Kantor and Edgar (1996) ${ }^{10}$ observed that computing was generally accepted as an integral component of teaching design, but that it hadn't significantly permeated the rest of the curriculum. They specifically stated that "at most institutions, thermodynamics is not taught any differently than it was 30 years ago." The survey results suggest that this perception is becoming outdated. Table 1 shows that only $20 \%$ of departments reported that process simulation software is used only in the design course, and Tables 2 and 3 show that it is particularly prevalent in the teaching of Equilibrium Staged Operations, Process Control and Thermodynamics.

Table 1 also indicates that approximately one-third of the responding departments felt that their faculty have "an overall, uniformly applied strategy for teaching simulation to their students which starts early in the program and continues in subsequent courses." Other respondents acknowledged the merit of such a plan but cited interpersonal obstacles, with comments such as:

I wish I had a vision, with each faculty member having their own pet piece of software, its tough to come to a consensus. There is also the influence of college decisions to teach MATLAB during the first year, and the math department's decision to use Maple, for example, which have to be integrated into departmental decisions.

Not many faculty use ASPEN in their courses because they haven't learned it, think it will take too much time to learn, and aren't motivated to do so.

I would like to see the use of flowsheet simulators expanded to other courses in our curriculum but haven't been able to talk anybody else into it yet.

Table 4 summarizes the responses to a question on motivation for using simulation software. Four options were given and the respondent was asked to check all that apply. The most commonly chosen option was "It's a tool that graduating chemical engineers should be 
familiar with, and is thus taught for its own sake." $83 \%$ of the respondents selected this option, and in $15 \%$ of responses it was the only one chosen. In their 1996 study of computer skills in chemical engineering, Kantor and Edgar (1996) surveyed both faculty and practicing engineers. They found that faculty tended to drastically under-estimate the time spend at the computer by practicing engineers in industry. The main software tool used being spreadsheets (74\%), graphics presentation packages (80\%), database systems $(70 \%)$ and electronic communications $(89 \%)$. These facts certainly do not invalidate the opinion that process simulation software is "a tool that graduating chemical engineers should be familiar with." They do, however, imply that programs would do well to examine whether they spend too much time on activities that familiarize students with the software but serve no other purpose.

Another finding of the Kantor and Edgar (1996) study was that computer programming (in languages such as FORTRAN, C or PASCAL) is not a vital skill for chemical engineers in industry. Indeed, "many companies explicitly tell their engineers not to write software because of the difficulty of maintaining such programs written by individuals." However, courses on computer programming appear to remain a staple of undergraduate chemical engineering programs. Table 5 shows that $79 \%$ of programs responding require a computerprogramming course (taught by either computer science or engineering faculty) and $38 \%$ of programs require programming in "several" subsequent courses. Respondents whose departments do not require programming commented that it had been recently phased out of their programs. This is a trend that may well grow. The 1996 CACHE survey indicates that $5 \%$ of respondents said it "is not important" to teach computers to undergrads, and 57\% thought it was "becoming less important." In addition, the current ABET Chemical Engineering criteria (http://www.abet.org/eac/eac.htm) requires that graduates have a knowledge of "appropriate modern experimental and computing techniques" but does not mention programming specifically, as it did in the past.

\section{Summary of 2001 Academic Survey}

The preliminary results of the survey conducted are shown in the following tables.

\section{Table 1: Response to "Which of these best describes your department's use of process simulation software?"}

\begin{tabular}{|l|c|}
\hline Response & \% Yes \\
\hline $\begin{array}{l}\text { The faculty has an overall, uniformly applied strategy for } \\
\text { teaching simulation to their students which starts early in the } \\
\text { program and continues in subsequent courses. }\end{array}$ & $38 \%$ \\
\hline $\begin{array}{l}\text { There is some coordination between individual faculty members, } \\
\text { but the department as a whole has not adopted a curriculum-wide } \\
\text { strategy. }\end{array}$ & $24 \%$ \\
\hline $\begin{array}{l}\text { Several instructors use it at their discretion but there is little or no } \\
\text { coordination. }\end{array}$ & $17 \%$ \\
\hline $\begin{array}{l}\text { Only the design instructor requires the use of chemical process } \\
\text { simulation software. }\end{array}$ & $24 \%$ \\
\hline
\end{tabular}


Table 2: Response to "Please indicate the courses in which professors require the use of Steady-State Chemical Process Simulation programs."

\begin{tabular}{|l|c|}
\hline Course & \% Yes \\
\hline Design I and/or II & $100 \%$ \\
\hline Process Safety & $7 \%$ \\
\hline Process Dynamics and Control & $10 \%$ \\
\hline Unit Operations & $45 \%$ \\
\hline Equilibrium Staged Operations & $62 \%$ \\
\hline Chemical Reaction Engineering & $24 \%$ \\
\hline ChE Thermodynamics & $45 \%$ \\
\hline Fluid Mechanics & $7 \%$ \\
\hline Heat Transfer & $14 \%$ \\
\hline Chemical Principles & $38 \%$ \\
\hline
\end{tabular}

Table 3: Response to "Please indicate the courses in which professors require the use of Dynamic Chemical Process Simulation programs."

\begin{tabular}{|l|c|}
\hline Course & \% Yes \\
\hline Design I and/or II & $3 \%$ \\
\hline Process Dynamics and Control & $55 \%$ \\
\hline
\end{tabular}

Table 4: Response to "Which of the following best describes your motivation to use simulation packages? Please check all that apply."

\begin{tabular}{|l|c|}
\hline Response & \% Yes \\
\hline It helps to illustrate essential chemical engineering concepts. & $69 \%$ \\
\hline It makes numerical computations less time consuming. & $66 \%$ \\
\hline The modernity is good for attracting and retaining students. & $24 \%$ \\
\hline $\begin{array}{l}\text { It's a tool that graduating chemical engineers should be familiar with, } \\
\text { and is thus taught for its own sake. }\end{array}$ & $83 \%$ \\
\hline
\end{tabular}


Table 5: Response to "Which of the following best describes your department's use of computer programming languages?"

\begin{tabular}{|l|c|}
\hline Response & \% Yes \\
\hline $\begin{array}{l}\text { One required course taught by computer science and no programming } \\
\text { required in subsequent chemical engineering courses. }\end{array}$ & $17 \%$ \\
\hline $\begin{array}{l}\text { One required course taught by chemical engineering and no } \\
\text { programming required in subsequent chemical engineering courses. }\end{array}$ & $10 \%$ \\
\hline $\begin{array}{l}\text { After students take the required programming course, they are required to } \\
\text { program in one subsequent ChE course. }\end{array}$ & $14 \%$ \\
\hline $\begin{array}{l}\text { After students take required programming course, they are required to } \\
\text { program in several subsequent ChE courses. }\end{array}$ & $38 \%$ \\
\hline $\begin{array}{l}\text { Students are required to program in upper level chemical engineering } \\
\text { courses without having taken a formal programming course. }\end{array}$ & $7 \%$ \\
\hline None of the above selected & $24 \%$ \\
\hline
\end{tabular}

Table 6: Response to "Indicate the mathematical applications software required of chemical engineering undergraduates"

\begin{tabular}{|l|c|}
\hline Response & \% Yes \\
\hline POLYMATH & 11 \\
\hline MATLAB & $34 \%$ \\
\hline Maple & $52 \%$ \\
\hline MathCAD & $21 \%$ \\
\hline EZ-Solve & $34 \%$ \\
\hline Spreadsheets & $7 \%$ \\
\hline Mathematica & $90 \%$ \\
\hline Other & $7 \%$ \\
\hline
\end{tabular}

Examples of Chemical Process Simulators in Chemical Engineering

In this section of the paper we attempt to give the reader some practical ideas on how they can easily and effectively implement chemical process simulators course other than the capstone design course.

\section{Freshman Engineering}

A good example for introducing freshmen or sophomores to chemical process simulators is to use an inductive approach. First show the students a heat exchanger. This can be either a laboratory unit or part of a cogeneration plant. ${ }^{12}$ The students should be asked to record their observations of fluid flowrate and temperatures. Then have the students start a process simulator and put these experimental results into simple heater unit operation of a process simulator to determine the heat duty. Next have the students conduct an energy balance by hand on the system. In this manner the students have first seen the equipment and then modeled it using a simulator and hand calculations. This helps the student to see how simulation works. 


\section{Chemical Principles or Stoichiometry}

In many programs with vertical integration of design throughout the curriculum the design project starts in this typically sophomore level course. Many examples of projects can be found in the literature. Bailie et al (1994) ${ }^{13}$ proposed a design experience for the sophomore and junior years. At the first semester of the sophomore year, the students are given a single chemical design project and they focus on material balances and simple economic evaluations such as raw material cost and products selling prices. Throughout the sequence, the students are required to applied new acquired knowledge to improve and optimize the process. The ultimate goal, by the end of the junior year, being a fully sized and optimized design including the analysis of the capital and operating costs. This approach is comparable to problem-based learning ${ }^{14}$. Douglas E. Hirt (1998) ${ }^{15}$ describes a similar model to that used at West Virginia by Baile et al. (1998). In Clemson's model, the students are given a case study to start working at the first-semester of their sophomore year where they are introduced to simple flow sheeting and mass and energy balances. The sequence involves seven courses and it ends at the fall semester of the senior year. Another contributions to this vertical integration can be found in Gatehouse et al. (1999) ${ }^{16}$ and in Shaeiwitz (2001) ${ }^{17}$. In all the above work it is unclear how specifically process simulators are being utilized and if they are use at all in the early stages of the integration.

\section{Chemical Principles - Energy Balances}

In Chapter 6 on multiphase systems in Felder and Rousseau ${ }^{18}$ the concept of a bubble and dew point are introduced. An inductive method of teaching these concepts is to start with an experiment on a binary system, using a $1 \mathrm{~L}$ distillation unit, or an interactive computer module ${ }^{19}$ with a visual examination of the bubble and dewpoint. These methods would result in the students examining their data using a binary T-x-y diagram. The next step is to use the process simulator to predict bubble and dewpoints for binary and multicomponent systems. In using HYSYS, the dewpoint temperature is automatically calculated after specifying i) the vapor fraction as 1.0 (dewpoint), ii) the compositions and iii) pressure in a single stream. The calculations for multicomponent systems are usually reserved for an Equilibrium Staged Operations course.

\section{Equilibrium Staged Operations}

Multicomponent flashes are usually introduced in either the chemical equilibrium thermodynamics course or the equilibrium stage course. Since in many curriculums the equilibrium staged operations course precedes the thermodynamics course, then the simulation of flashes are very appropriate for this course. Multicomponent isothermal or adiabatic flashes can be simulated very easily by adding a gas-liquid separator unit operation to the process flow diagram of the simulator as shown in Figure 1. The next step would be to ask the students to perform flash calculation by hand for 3 components using the modified DePriester charts contained in almost all relevant texts. ${ }^{20}$ The professor must require that the students submit the sample hand

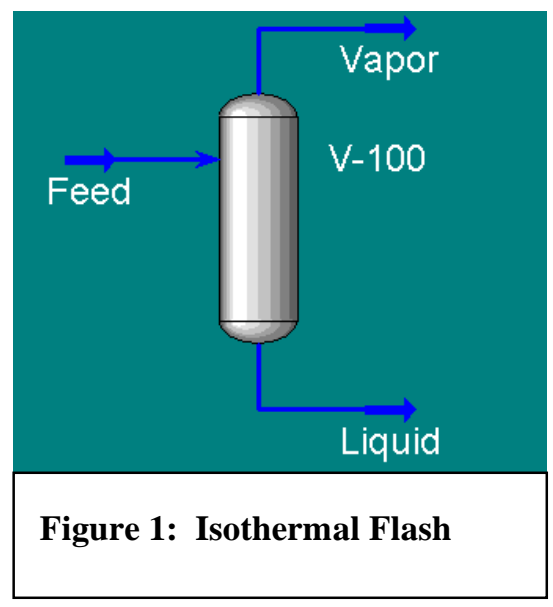

Figure 1: Isothermal Flash 
calculations and either the spreadsheet or POLYMATH program for the solution of this problem $^{21}$. The process simulator solution can act as a guide for the students to obtain the solution using the K-values. In this manner, the student will use approximate equations, Kvalues, to understand how the computer is solving this simple problem. At this point the student is ready to understand multiple equilibrium stage operations.

In teaching distillation, almost all faculty throughout the world use the McCabe Thiele graphical method. This is an excellent tool to introduce students to binary distillation problems. Before extensive use of the computer the next step was to add the energy balance and use the Ponchon-Savarit method, now many professors do not teach this method and instead use the simulator. This decreasing use of Ponchon-Savarit has been promoted by Wankat et al. ${ }^{22}$ and recently published textbook descriptions of the method have been shortened $^{23}$.

A possible solution to these concerns about lack of faculty time and motivation is implementing mini-modules of the type used in the Rowan University Chemical Engineering Department. For example, in Equilibrium Staged Operations, among the concepts a student must learn are the optimum feed location, and the improved separation resulting from increasing reflux ratio for a given number of stages. An approach that has been used at Rowan University is:

- The instructor prepares a complete HYSYS model of a distillation column and distributes it to the class.

- The class receives a brief (<5 min.) tutorial on modeling columns with HYSYS- just enough to tell them how to change specific parameters such as the reflux ratio and where to locate the resulting stream compositions.

- The students take a column through a series of configurations, varying the reflux ratio, number of stages and feed stage location, and answer a series of questions about the results. The students are thus introduced to the concepts in an inductive manner.

- Subsequent classroom instruction further examines the "whys" of the results.

Mini-modules analogous to this have been integrated throughout the course, as well as Thermodynamics and Principles of Chemical Processes. The primary purpose of the modules is that the HYSYS model provides a time-efficient and effective way for the students to examine the cause-effect relationships among column operational parameters. The modules also serve a curricular purpose in that they begin to introduce process simulation. Because of the narrow scope of each module, students don't gain any real expertise in using the software, but they do gain an appreciation of its power and value, and start to learn to distinguish problems that can be solved with simulation from those that cannot. All this is accomplished with a minimal requirement of faculty time. It is not necessary for the faculty member to learn the simulation package in detail; he or she merely needs to learn how to model one particular unit operation.

Other forms of mini-modules have been proposed. Lewin and Seader ${ }^{1,4}$ have developed a series of self-paced web modules for HYSYS and ASPEN. It has been proposed that these modules be given to the students and the professor does not need to prepare these time 
consuming tutorials and it has been suggested that the professor may not need to learn how to use the simulator. Another paper by Chittur $(1988)^{24}$ discusses preparing tutorials for ASPEN Plus simulators using HTML. Finally the University of Florida maintains a web site for ASPEN in which tutorials are available. ${ }^{25}$

\section{Thermodynamics}

From the preliminary results from our survey, it seems that process simulators are now being widely used in thermodynamics (see Table 2). It is clear that is a fertile ground for a pedagogical use of process simulators. The first thing a new-user of a simulator faces is the variety of thermodynamics packages available. The first hard lesson this new user soon will learn is that an incorrect choice will yield meaningless results regardless of the convergence of the simulation case. Unfortunately, there are so many thermodynamics models in commercial simulators that it would be impossible to educate our students in each one of them. Elliot and Lira (1999) ${ }^{21}$ in their recent textbook present a decision tree for the proper selection of the thermodynamic model. With simulators been capable of solving complex multiphase equilibrium problems and predicting thermodynamic properties (enthalpy, entropy, transport properties, etc), the question now is whether there is still value in the longestablished approach to teaching thermodynamics. Traditionally, students are taught how to perform equilibrium and properties calculations by hand or, in the best scenario, by the aid of custom made software programs for hand calculators or computers. The increasing influence of process simulators opens up a complete new spectrum of possibilities. Since simulation results are always as good as the decision on the thermodynamic package, would not it be of value to devote time to teach the fundamental aspects that will permit students to intelligently pick the right thermodynamics for a system. Simulators also offer the advantage of the possibility of combining different thermodynamic models in the same simulation and even picking different model for certain properties within the overall model. PRO II w/Provision is very versatile in this aspect, for instance, a equation of sate such as SRK is chosen as the overall simulation package but it is modified so liquid density is calculated using the API equation.

The prediction of thermodynamic properties has undergone a large change in chemical engineering research and their subsequent use in chemical process simulation programs. In many cases, professors have been taught thermodynamics using earlier versions of Sandler ${ }^{26}$ and Smith and Van Ness ${ }^{27}$ which did not have predictions of thermodynamic properties based on an equation of state. In more recent texts of Sandler (1998) and Smith and Van Ness $\left(5^{\text {th }}\right.$ ed 1996) and new texts such as by Elliott and Lira now contain at least a chapter devoted to predicting thermodynamic properties from equations of state. Since students are using these property estimations, then one of the fundamental aspects of a modern chemical thermodynamics course is to teach students not only how to use these equations, but which equation of state they should select for a particular problem. An example of the prediction of the enthalpy of a single component is given below where the values of $a=f(T)$ and $b$ are from the Peng-Robinson equation of state.

$$
\frac{\left(H-H^{i g}\right)}{R T}=Z-1-\ln \left[\frac{Z+(1+\sqrt{2}) B}{Z+(1-\sqrt{2}) B}\right] \frac{A}{B \sqrt{8}}\left[1+\frac{\kappa \sqrt{T_{r}}}{\sqrt{\alpha}}\right]
$$

where 
$B \equiv b P / R T$ and $A \equiv a P /(R T)^{2} \therefore$

From the above equations it can be easily seen how complicated these predictions can become compared to a Table or a graph in a standard handbook. ${ }^{28,29}$ What many of the recent thermodynamic textbooks have done is give computer programs that allow the reader to use these equations to solve related homework problems. Instead of using these textbook computer programs, the professors should be using the thermodynamic packages contained in the chemical process simulators. In this manner, the students will be very familiar with the options that are available in the various simulators.

\section{Chemical Reaction Engineering}

In the current chemical reaction engineering course most students are familiar with ODE solvers found in POLYMATH or MatLab. The philosophy given by Fogler $^{30}$ is to have the students use the mole, momentum and energy balances appropriate for a given reactor type. In this manner a fairly detailed model of a reactor can be developed of industrial reactors for design projects ${ }^{31}$. Using POLYMATH or MatLab a student can easily see the equations used to model the reactor. In modern process simulators there are several reactors that can be used. For example in HYSYS 2.2 there are the two ideal reactor models of a CSTR and a PFR. The CSTR model is a standard algebraic model that has been in simulation packages for a number of years. The ODE's of the PFR are a recent addition to simulation packages and are solved by dividing the volume into small segments and finding a sequential solution for each volume. In these more recent models, these reactors not only include energy balances, but pressure drop calculations are a standard feature for packed bed reactors.

Within each of these reactors there are subsets of how the reactants and products are modeled:

\begin{tabular}{|c|c|}
\hline Reaction Type & Description: \\
\hline Conversion & $F_{i}=F_{i 0}-F_{A 0} X_{A}$ \\
\hline Equilibrium & $\begin{array}{l}K_{e q}=f(T) ; \text { equilibrium based on reaction stoichiometry. } \\
K_{e q} \text { predicted or specified }\end{array}$ \\
\hline Gibbs & minimization of Gibbs free energy of all components \\
\hline Kinetic & $\begin{array}{l}r_{A}=-k_{f} C_{A}^{\alpha} C_{B}^{\beta}+k_{r e v} C_{R}^{\varphi} C_{S}^{\gamma} \text { where the reverse rate parameters } \\
\text { must be thermodynamically consistent and rate constants are } \\
\text { given by } k=A T^{n} \exp (-E / R T)\end{array}$ \\
\hline $\begin{array}{l}\text { Heterogeneous } \\
\text { Catalytic }\end{array}$ & $\begin{array}{l}\text { Yang and Hougen form: } \\
-r_{A}=\frac{k\left(C_{A}^{a} C_{B}^{b}-\frac{C_{R}^{r} C_{S}^{s}}{K}\right)}{1+\sum K_{i} C_{i}^{\gamma_{i}}} \\
\text { This form includes Langmui-Hinshelwood, Eley-Rideal and } \\
\text { Mars-van Krevelen etc. }\end{array}$ \\
\hline Simple Rate & $\begin{array}{l}r_{A}=-k_{f}\left(C_{A}^{\alpha} C_{B}^{\beta}-\frac{C_{R}^{\varphi} C_{S}^{\gamma}}{K_{e q}}\right) \text { in which } K_{e q} \text { is predicted from } \\
\text { equilibrium data. }\end{array}$ \\
\hline
\end{tabular}


With the above set of reactions, chemical reaction engineering courses can easily use the process simulator. There are at least two choices that can be used in teaching chemical reaction engineering with process simulators. The first case is to have the students use the simulators in parallel with the textbook. The second case is to introduce the simulator in the last $1 / 3$ of the course. If the first approach is chosen then the professor will need to require that the students show sample calculations for all of their work.

In using process simulators the professor has a dilemma on the amount of hand calculations that a student should conduct. For example, in predicting an equilibrium constant as a function of temperature Rowan students naturally drifted to the process simulator to obtain Gibbs free energies as a function of temperature. In this assignment, I required that they calculate the Gibbs free energy from the standard heats of formation and correct it for temperature using the integrated Van't Hoff expression as given in Appendix C of Fogler's text $^{30}$. In addition for the dehydrogenation of ethylbenzene forming styrene and hydrogen, the predicted equilibrium constant, $K_{P}$, has units of atm based on the standard state of $1 \mathrm{~atm}$. In hand calculations, many of the students assumed inappropriate units for the standard state and could not obtain reasonable values of the equilibrium conversion. If the students had used the HYSYS equilibrium reactor, then a graph of $K_{P} v s . T$ is automatically produced. The question is then raised, do students need to spend several hours of spreadsheet calculations to obtain a graph of $K_{P} v s . T$ ?

\section{Rate Based Separations}

An example of an integrated approach to teaching rate-based separations with design is given by Lewin, Seider and Seader (1998) ${ }^{32}$. In this paper the state that the Design courses are fully utilizing the advances in modern computing through the process simulators, but many of the other courses in the curriculum are still using methods employed over 60 years ago. Many of these methods are visual and are very useful in teaching chemical engineering concepts, but students are not being prepared for the future use of simulators. The authors suggest that professors who teach the junior course(s) in separations, equilibrium-stage operations, ratebased operations, and/or mass transfer consider including the following topics which are similar to Chapters 9 through 12 in the new Seader and Henley text ${ }^{23}$ :

- $\quad$ approximate methods (Fenske-Underwood-Gilliland and Kremser algebraic method);

- rigorous multicomponent

- enhanced distillation utilizing triangular diagrams

- Rate based methods contained ChemSep program and the RATEFRAC program of ASPEN PLUS

- adsorption, ion exchange, chromatography

- membrane separations

One major drawback in current process simulators is the lack of standard unit operations for membrane and other novel separators. This can be partially addressed by importing programs into the process simulators. For example on HYSYS's web site an extension program can be downloaded for a membrane separator. ${ }^{33}$

\section{Future and Current Use of Simulators in Industry}

There is though a caveat in this suggested pedagogical approach that is the fact that a large number of the current and future chemical engineers employers are small firms that cannot afford the commercial licensing fees of a process simulator. At Rowan Engineering, we have 
had a clear example of this. In the Fall of 1999 a small consulting engineering company was assisting a senior design group of students and one of the engineers brought in a "homemade" excel macro to calculate the vapor pressure of a mixture of VOC. When asked why his company was not using simulators instead of spending time creating these macros, his reply was: " we cannot afford them".

We believe that this trend will not continue and that the licensing fees will go down as the demand increases. Computer usage and technology will continue to grow and the chemical engineering profession must provide the future engineer

\section{Conclusions}

Chemical process simulation is currently underutilized in the chemical engineering curriculum. According to the preliminary results of our survey, process simulators are used in all design courses and are also heavily used in equilibrium stage operations primarily with respect to multicomponent distillation. We would like to see the use of process simulation increase in other courses in chemical engineering. Chemical engineering departments need to prepare students for the increasing future use of these programs. Process simulation companies also need to improve their programs by adding new and innovative unit operations as well as continuing to improve their thermodynamic models.

This paper contains many practical suggestions and references for faculty members to implement a unified strategy for teaching simulation to their students which starts early in the program and continues in subsequent courses. We believe that simulation packages are a fundamental tool for the future chemical engineer.

\footnotetext{
${ }^{1}$ Seider, Warren D., J. D. Seader, Daniel R. Lewin, Process Design Principles: Synthesis, Analysis and Evaluation, John Wiley and Sons, 1999

${ }^{2}$ GAMS see http://www.che.utexas.edu/cache/newsletters/fall97_art2.pdf

${ }^{3}$ Aspen Technology, Inc

${ }^{4}$ Lewin, D. R. W. D. Seider, JD Seader, Teaching Process Design: An Integrated Approach, AIChE Paper 63d, 2000 AIChE Annual Meeting, Los Angeles.

${ }^{5}$ Phillip C. Wankat, “Equilibrium Staged Separations”, Elsevier, 1988.

${ }^{6}$ Michael A. Henson and Yougchun Zhang, "Integration pf Commercial Dynamic Simulators into the Undergraduate Process Control Curriculum”. Proceedings of the AIChE Annual Meeting, Los Angeles, CA, Nov. 2000.

${ }^{7}$ David E. Clough, “ Using Process Simulators with Dynamics/Control Capabilities to Teach Unit and Plantwide Control Strategies". Proceedings of the AIChE Annual Meeting, Los Angeles, CA, Nov. 2000.

${ }^{8}$ Colin S. Howat, "Process Simulation in Chemical Engineering Design: A Potential Impediment to, Instead of Catalyst for, Meeting Course Objectives," Session 36131988 ASEE Annual Conference.

${ }^{9}$ A. S. Foss, K. R. Guerts, P. J. Goodeve, K. D. Dahm, G. Stephanopoulos, J. Bieszczad, A. Koulouris, "A Phenomena-Oriented Environment for Teaching Process Modeling: Novel Modeling Software and Its Use in Problem Solving," Chemical Engineering Education, Fall 1999.

${ }^{10}$ Jeffrey C. Kantor and Thomas F. Edgar, "Computing Skills in the Chemical Engineering

Curriculum”.Computers in Chemical Enginerring, CACHE Corp., 1996.

${ }^{11}$ Cutlip, M. B. and M. Shacham, Problem Solving in Chemical Engineering with Numerical Methods, Prentice Hall PTR, Upper Saddle River, NJ 1999.
} 
${ }^{12}$ Hesketh, R. P. and C. S. Slater, "Using a Cogeneration Facility to Illustrate Engineering Practice to Lower Level Students," Chemical Engineering Education, 33 (4) 316 Fall 1999.

${ }^{13}$ Bailie, R.C., J. A. Shaeiwitz, and W.B. Whiting, "An Integrated Design Sequence", Chemical Engineering Education, 28(1) 52 (1994).

${ }^{14}$ D.R. Woods, "Problem-Based Learning: How to Gain the Most from PBL", W.L. Griffin Printing Limited, Hamilton, Ontario, Canada, 1994.

${ }^{15}$ Hirt, Douglas, "Integrating Design Throughout the ChE Curriculum: Lessons Learned," Chemical Engineering Education, 32(4) 290, (1998).

${ }^{16}$ Ronald J. Gatehouse, George J. Selembo Jr., and John R. McWhirter, "The Vertical Integration of Design in Chemical Engineering," Session 2213, Proceedings of the 1999 ASEE Annual Conference.

${ }^{17}$ Shaeiwitz, J. A., "Chemical Engineering Design Projects," http://www.cemr.wvu.edu/ wwwche/publications/projects/index.html, viewed on 15 March 2001

${ }^{18}$ Felder, R. M., and R. W. Rousseau, "Elementary Principles of Chemical Processes," $3^{\text {rd }}$ Ed. John Wiley \& Sons, Inc., New York, (1999).

${ }^{19}$ Montgomery, S. "The Multimedia Educational Laboratory," http://www.engin.umich.edu/labs/mel/.

${ }^{20}$ Wankat, P. C., "Equilibrium Staged Separtions," Prentice Hall PTR, Engelwood Cliffs, NJ, 1988.

${ }^{21}$ J. Richard Elliot and Carl T. Lira, "Introductory Chemical Engineering Thermodynamics", Prentice Hall PTR, 1999.

${ }^{22}$ Wankat, P. C., R. P. Hesketh, K. H. Schulz, and C. S. Slater, "Separations - What to Teach Undergraduates." Chem. Eng. Educ., 28 (1) 12 (1994).

${ }^{23}$ Seader, J. D., E. J. Henley, “Separation Process Principles,” John Wiley \& Sons, Inc., New York, 1998.

${ }^{24}$ Krishnan K. Chittur, "Integration of Aspenplus (and other Computer

Tools) into the Undergraduate Chemical Engineering Curriculum," 1988 ASEE Annual Conference Session 3613.

${ }^{25}$ Kirmse, Dale, ASPEN PLUS Virtual Library, http://aspen.che.ufl.edu/ viewed 15 March 2001.

${ }^{26}$ Sandler, Stanley I. Chemical and Engineering Thermodynamics, New York : John Wiley and Sons, 1977

${ }^{27}$ Smith, J. M.; H. C. VanNess- "Introduction to Chemical Engineering Thermodynamics," 3rd ed., New York, McGraw-Hill, 1975.

${ }^{28}$ Engineering Data Book, Gas Processors Suppliers Association, Tulsa OK, $10^{\text {th }}$ ed. 1987.

${ }^{29}$ Perry's Chemical Engineers' Handbook, R. H. Perry and D. W. Green eds., $7^{\text {th }}$ Ed. McGraw Hill 1997.

${ }^{30}$ Fogler, H. Scott, "Elements of Chemical Reaction Engineering," $3{ }^{\text {rd }}$ Ed., Prentice Hall PTR, Upper Saddle River, NJ, 1999.

${ }^{31}$ R. P. Hesketh, "Incorporating Reactor Design Projects into the Course," Paper 149e, 1999 AIChE Annual Meeting, Dallas, TX, 31 October - 5 November 1999.

${ }^{32}$ J. D. Seader, Warren D. Seider, and Daniel R. Lewin, "Coordinating Equilibrium-based and Rate-based Separations Courses with the Senior Process Design Course," Session 3613, Proceedings of the 1998 ASEE Annual Conference.

${ }^{33}$ HYSYS Programmability / Extensibility (OLE) Examples, http://www.hyprotech.com/ole, viewed 15 March 2001. 